\title{
试析在小学语文教学中学生写作兴趣的培养策略
}

付兴金

DOI:10.32629/jief.v2i7.1999

[摘 要] 语文是学习其他学科的重要基础, 语文中的写作是学生表达情绪、进行创作的重要途径, 因此学生需要熟练掌握运用和表达文字的 能力。小学生尚且处于对新学事物都好奇的阶段, 所以小学语文是学生提起对文字写作兴趣的关键时期。写作教学中, 应贴合学生实际情况, 引导学生关注现实生活, 敢于表达自己的真情实感。本文通过结合教材和现实情况对语文写作兴趣的培养进行探究讨论。

[关键词] 小学语文教学; 写作兴趣; 培养方法

中图分类号: G623 文献标识码: A

在有些学生写作时, 会出现无从下笔、内心焦躁不安的现象, 往往 创作出来的文章题材单调陈旧无亮点、内容千篇一律无新意。这种状况 的出现原因是在写作中首先想到的不是自己的亲身感受和经历, 而是自 己曾经见到的作文中的素材。再一个就是学生阅读量少导致积累的词汇 句式少，即使有真情实感也无法准确自然地表达出来。此时教师就应该 根据问题来帮助学生开拓思维, 引导学生自主积累好词好句, 提高学生 对语文写作的兴趣。

\section{1 小学语文写作教学的问题}

现在许多教师在教授学生写作时, 仍旧采用传统保守的方式。例如 让学生写作时直接套用作文模板, 使学生缺少思考, 局限学生思维或者 死板地讲授写作文时的知识点并进行大量的写作练习, 以致于学生丧失 写作时的自主性, 使得学生渐渐丧失对写作的兴趣。慢慢的, 学生只将 写作认为是老师留下的任务来完成, 在面对写作时就会出现恐惧和厌倦 的心理, 最终可能会致使学生的写作能力进步缓慢甚至下降。

\section{2 培养学生写作兴趣的方法}

2.1 增加学生阅读时间, 提高学生阅读兴趣

阅读是写作的灵感和源泉, 学生在通过阅读时会逐渐对文字产生兴 趣, 还会积累大量好词好句、开阔学生的思维。教师在布置作业时, 尽 量多布置一些阅读书籍的任务。刚开始可以让学生自由阅读自己感兴趣 的书籍, 积累到一定程度时, 可由教师推荐几本内涵丰富、百读不厌、 值得回味的名著进行摘抄, 同时让学生记录下自己在阅读时产生的想法 和感受。比如在龟兔赛跑的故事中, 可让学生学习到不要像兔子那样骄 傲自大、轻视对手, 应该学习乌龟坚持不解、奋力向前的精神。阅读和 写作时细水长流的事情, 欲速则不达, 可安排具体的雷打不动的时间段 来进行阅读, 让学生保持良好的阅读习惯。

2.2 培养学生善于观察的习惯, 体验生活中的写作素材

学生写作时的文章应该是由生活中所发生的事例和从从中有感而发 的情绪和思考构成的, 所以学生周围的环境和发生的事情是学生写作的 重要材料。教师应引导学生学会观察, 根据写作的需要来确定观察的对 象, 观察事物或现象时要由表及里, 可通过询问学生根据事物或事件从 中感受认识到什么, 借此来引发学生思考, 拓展学生的思维。例如教师 可以组织学生进行一些益智的游戏或者公益的活动, 体会生活中的善良 和热情, 让学生根据自己的理解和感受写一篇作文。

2.3 培养学生想象空间, 开拓学生思维

小学生年龄尚小, 对所有事物都好奇, 有着天马行空的想象力。教 师也应该根据这一特点对学生进行合理的引导, 充分利用小学生发散性 的思维, 将其运用到作文的创造中。教师可以通过一段生动描写的文字 或悦耳的音乐让学生自由想象画面, 再让学生根据自己的想象重新描写 勾勒画面, 由此提升学生的想象空间。教师要多鼓励学生思考, 培养学 生善于思考的能力, 开拓学生的思维, 来提升学生的表达能力。

2.4 进行多样化教学, 增加学生的学习兴趣
由于教学模式的单调性, 会使学生产生学习疲㤂, 从而丧失学习兴 趣。由此可知, 教师在教授写作时需采用多种教学形式。师可以将学生 进行分组, 让小组之间进行演讲比赛、心得比赛、作文比赛、词组比赛 等多种形式的活动。小学生天生好动、活泼, 拥有极大地胜负欲, 渴望 取得优异的成绩, 所以在面对比赛时会格外认真, 全力以赴准备比赛。 小组之间的成员肯定会有不同的想法和意见, 在各种想法的碰撞之下, 会让学生的思维更加开阔, 视野也会更为开阔, 学生的学习兴趣会被激 发。

2.5 做好批改发现亮点, 激发学生写作自信

学生学习写作的过程中, 他人的认可和鼓励是激发学生学习的动力。 老师在批改学生的作文时, 不仅要将学生的错误指出, 还需要在最后加 上一句鼓励或者赞美的话, 让学生认识到自己的努力没有白费, 这也可 以培养学生的写作自信。老师批完作文之后可将作文再次让学生自主修 改、完善, 提高学生的修改能力。在发现学生优秀的作文之后, 可以将 作文作为范文进行诵读并进行讲解, 让其他学生学习的同时增加了学生 写作的积极主动性。

2.6 教授学生写作方法, 运用写作技巧

教师可以利用几篇优秀的例文进行示范, 依据学生写作水平, 进行 相应程度的讲解。勾画出其中所用到的技巧比如拟人、比喻、排比等手 法, 让学生进行仿写来提升学生的写作水平。知识类讲解一般较为枯燥, 需活跃课堂气氛来提高学生注意力以此让学生更好掌握方法和技巧。如 在讲解怎样描写人物时, 教师可以提供一张人物图片让学生先自己描写, 最后显示范例, 让学生进行自己比对, 在提高学生注意力的同时也能提 高学生自主学习的能力。

\section{3 总结}

小学写作教学的模式多样, 教师需不断创新教学方式, 转变教学理 念。学生写作能力的提高不是一日之功, 需要日积月累, 循序渐进的付 出和努力。写作能够体现出学生的综合素质, 在生活中的用途广泛, 因 此, 写作能力需要从小培养。学习写作中最重要的便是激发学生对于写 作的兴趣, 教师的鼓励和正确有效的教学方式对学生的写作自信和学习 兴趣的激发有很大作用。

\section{[参考文献]}

[1]沈雪珺.基于部编版教材培养低段小学生语文素养的策略探究 [J].课程教育研究,2019(52):175-176.

[2]陈丹凤.有效开展语文综合实践全面培养学生语文素养[J]. 学周 刊,2018(81):98-99.

[3] 徐娜娜.浅析小学语文教学课堂读写训练策略 [J]. 新课 程,2020(34):39.

作者简介：付兴金 (1989-), 女, 汉族, 山东临沂罗庄人, 大 学本科学历, 二级教师, 研究方向: 小学语文, 汉语言文学研究 